\title{
Role of color doppler in the diagnosis of intra uterine growth restriction (IUGR)
}

\author{
Shivani Singh ${ }^{1} *$, Urvashi Verma ${ }^{2}$, Kumkum Shrivastava ${ }^{1}$, Sachin Khanduri ${ }^{1}$, Nancy Goel ${ }^{1}$, \\ Fatima Zahra ${ }^{1}$, K. L. Shirivastava ${ }^{1}$
}

\begin{abstract}
${ }^{1}$ Department of Obstetrics and Gynecology, Era's Medical College \& Hospital, Lucknow, Uttar Pradesh, India
${ }^{2}$ Department of Obstetrics and Gynecology, S. N. Medical College, Agra, Uttar Pradesh, India
\end{abstract}

Received: 26 September 2013

Revised: 9 October 2013

Accepted: 11 October 2013

\section{*Correspondence:}

Dr. Shivani Singh,

E-mail: bundela.shivani@gmail.com

(C) 2013 Singh S et al. This is an open-access article distributed under the terms of the Creative Commons Attribution Non-Commercial License, which permits unrestricted non-commercial use, distribution, and reproduction in any medium, provided the original work is properly cited.

\begin{abstract}
Background: The purpose of our study was to evaluate the diagnostic efficacy of the pulsatility index (PI) and resistive index (RI) in uterine artery, umbilical artery and middle cerebral artery in the diagnosis of IUGR and prediction of adverse perinatal outcome.

Methods: A total of 100 clinically suspected IUGR cases were enrolled in the study. A detailed history and examination was done, color doppler carried out serially every three weeks starting from 30 weeks till delivery, subsequently confirmation of fetal growth restriction (FGR) was done by assessing the newborn parameters for growth restriction.

Results: Doppler measurement for uterine artery showed higher efficacy as compared to umbilical artery and middle cerebral artery findings. The uterine artery RI was found to be $84.6 \%$ sensitive and $82.9 \%$ specific even at 30 weeks. Uterine artery PI too showed a good diagnostic efficacy with an accuracy of 79\%, a sensitivity of $76.9 \%$, a specificity of $82.9 \%$.Both PI and RI for uterine artery showed a relatively higher specificity.

Conclusion: Here we concluded that once IUGR is suspected, Doppler velocimetry may be useful as a part of evaluation and uterine artery analysis identifies a subgroup with an increased risk for developing IUGR.
\end{abstract}

Keywords: Doppler, Foetal growth restriction, Resistance index, Pulsatility index

\section{INTRODUCTION}

The term fetal growth restriction is used when the fetal weight is less than the $10^{\text {th }}$ percentile for the gestational age or at least 2 standard deviation below the mean weight for their gestational age (Lubchenco). ${ }^{1}$ Incidence of IUGR is about $10 \%$ and it carries relatively poor prognosis because of increase perinatal morbidity and mortality. This is due to inadequate supply of oxygen and nutrients through the placenta, chromosomal anomalies and infections which adversely affecting the fetal outcome. The management of growth restricted fetus required accurate diagnosis to optimize the time of delivery .Placental insufficiency is the most common cause of IUGR, and the Doppler velocimetry is the only noninvasive method for assessing the fetoplacental hemodynamic status. It can be credited with causing a significant decrease in perinatal mortality and morbidity.

\section{METHODS}

It was a prospective study conducted at department of obstetrics \& gynae in collaboration with radiology and pediatrics, Era's Lucknow medical college and hospital. The duration of study was 18 months. A total of 100 clinically suspected IUGR cases were enrolled in the study. A detailed history and examination was done, color Doppler carried out serially every three weeks starting 
from 30 weeks till delivery, subsequently confirmation of fetal growth restriction (FGR) was done by assessing the newborn parameters for growth restriction.

Doppler ultrasound was performed using the macro convex probe $(3.5 \mathrm{MHz})$. Pulsed wave Doppler mode and color flow mapping with simultaneous real time B- mode ultrasound imaging was used to locate and record the umbilical, uterine and middle cerebral artery waveforms.

The recordings were made with an angle of insonation being 30-60 degrees and when at least four waves of equal height appeared on the screen. S/D ratio, resistive index ratio, pulsatility index ratio and peak systolic ratio were recorded.

Primary outcome considered at birth was: Presence or absence of fetal growth restriction. Following parameters were noted at the time of delivery:

A. Baby's weight measured on braun's weighing scale and recordings on lubchenco's normogram.

B. Length of the baby measured by infantometer

C. Pondral index (birth weight in grams/length incm3). Index of $<2$ indicate growth restriction. Secondary outcome noted at birth was:

A. Admission to NICU

B. Neonatal death

Management of patients was done as per the protocol of obstetrics and gynae department.

\section{RESULTS}

A Total of 100 clinically suspected IUGR subjects were enrolled for the purpose of this study. Determination of FGR was done by measuring the ponderal index of the babies at birth. Out of $100,65(65 \%)$ cases were finally confirmed to be FGR (pondral index<2.5) while $35(35 \%)$ were found to be normal or no FGR (pondral index $>2.5$ ).

On color Doppler, In Umbilical artery- statistically significant difference in RI of two groups was seen at all time intervals. The mean RI in non FGR group was maximum at 33 week $(0.69+-0.11)$ and thereafter it showed a decline at 36 weeks and finally reached to $0.65+-0.08$ at 39 week. In FGR group, the mean RI was maximum at 33 weeks $(0.81+-0.18)$ and minimum at 36 weeks $(0.70 \pm 0.12)$. At 39 weeks the mean RI in FGR group was $(0.70 \pm 0.13)$. At 30 week the cut of value of 0.68 was predicted to be $83 \%$ sensitive and $\& 74.3 \%$ specific with a positive predictive value of $85.2 \%$ and a negative predictive value of $66.7 \%$ considering the early detectability and maximum accuracy, the 30 weeks cut off value was evaluated for diagnostic accuracy. Overall diagnostic accuracy of the test was found to be $78 \%$.

The mean S/D ratio in non FGR group was maximum at 30 weeks $(2.93 \pm 0.80)$ and thereafter it showed a decline to finally reach to $2.44 \pm 0.71$ at 39 weeks in FGR group the mean S/D ratio was maximum at 36 weeks and minimum at 39 weeks (3.19 \pm 0.77$)$. Receiver- operator curve analysis showed maximum area under curve at 39 weeks (0.707) while minimum area under curve was seen at 30 weeks (0.706). At 33 weeks the cut of value off 3.13 was predicted to be $70.8 \%$ sensitive and 65.75 specific. Considering the early detectability, the 33 weeks cut off was evaluated for diagnostic accuracy. The 33 weeks S/D ratio> 3.13 showed to be $70.8 \%$ sensitive, $65.7 \%$ specific with a positive predictive value of $79.3 \%$ and a negative predictive value of $54.8 \%$. Overall diagnostic efficacy of the test was found to be $69 \%$.

Table 1: Umbilical artery resistive index analysis.

\begin{tabular}{|c|c|c|c|c|c|c|}
\hline \multirow{3}{*}{ SN } & \multirow{3}{*}{$\begin{array}{l}\text { Time } \\
\text { interval }\end{array}$} & \multicolumn{3}{|c|}{$\begin{array}{l}\text { Umbilical Artery Resistive Index } \\
\text { Group Comparison }\end{array}$} & \multicolumn{2}{|c|}{ ROC Analysis } \\
\hline & & $\begin{array}{l}\text { Non-FGR } \\
\text { Group }(n=35)\end{array}$ & $\begin{array}{l}\text { FGR Group } \\
(\mathrm{n}=65)\end{array}$ & \multirow{2}{*}{ P value } & Area & \multirow{2}{*}{$\begin{array}{l}\text { P value } \\
\left(H_{0}: \text { Area }=0.5\right)\end{array}$} \\
\hline & & Mean \pm SD & Mean \pm SD & & Mean \pm SD & \\
\hline 1 & $30 \mathrm{wk}$ & $0.66 \pm 0.05$ & $0.75 \pm 0.10$ & $<0.001$ & $0.822 \pm 0.042$ & $<0.000$ \\
\hline 2 & $33 \mathrm{wk}$ & $0.69 \pm 0.11$ & $0.81 \pm 0.18$ & $<0.001$ & $0.706 \pm 0.051$ & $<0.001$ \\
\hline 3 & $36 \mathrm{wk}$ & $0.61 \pm 0.07$ & $0.70 \pm 0.12$ & $<0.001$ & $0.765 \pm 0.047$ & $<0.000$ \\
\hline 4 & $39 \mathrm{wk}$ & $0.65 \pm 0.08$ & $0.77 \pm 0.13$ & $<0.001$ & $0.809 \pm 0.043$ & $<0.000$ \\
\hline
\end{tabular}

Umbilical artery resistive index (cut off value > 0.68 at 30 weeks) as a marker of FGR has sensitivity $80 \%$, specificity $74.3 \%$ with a positive predictive value $85.2 \%$ and a negative predictive value $66.7 \%$. Over all diagnostic accuracy was found to be $78 \%$. 
Table 2: Umbilical artery S/D ratio analysis.

\begin{tabular}{|c|c|c|c|c|c|c|}
\hline \multirow{3}{*}{ SN } & \multirow{3}{*}{$\begin{array}{l}\text { Time } \\
\text { interval }\end{array}$} & \multicolumn{2}{|c|}{$\begin{array}{l}\text { Umbilical Artery S/D Ratio } \\
\text { Group Comparison }\end{array}$} & \multicolumn{3}{|c|}{ ROC Analysis } \\
\hline & & $\begin{array}{l}\text { Non-FGR } \\
\text { Group }(n=35)\end{array}$ & $\begin{array}{l}\text { FGR Group } \\
(n=65)\end{array}$ & \multirow{2}{*}{$\mathrm{P}$ value } & Area & \multirow{2}{*}{$\begin{array}{l}\text { P value } \\
\left(H_{0}: \text { Area }=0.5\right)\end{array}$} \\
\hline & & Mean \pm SD & Mean \pm SD & & Mean \pm SD & \\
\hline 1 & $30 \mathrm{wk}$ & $2.93 \pm 0.80$ & $3.47 \pm 0.67$ & $<0.001$ & $0.706 \pm 0.001$ & 0.001 \\
\hline 2 & 33 wk & $2.75 \pm 0.73$ & $3.48 \pm 0.78$ & $<0.001$ & $0.746 \pm 0.000$ & 0.000 \\
\hline 3 & $36 \mathrm{wk}$ & $2.61 \pm 0.73$ & $3.21 \pm 0.64$ & $<0.001$ & $0.726 \pm 0.000$ & 0.000 \\
\hline 4 & 39 wk & $2.44 \pm 0.71$ & $3.19 \pm 0.77$ & $<0.001$ & $0.767 \pm 0.000$ & 0.000 \\
\hline
\end{tabular}

Umbilical artery S/D ratio as a marker of FGR (cut off value $>3.13$ at 33 weeks) has sensitivity $70.8 \%$, specificity $65.7 \%$ with a positive predictive value $79.3 \%$ and a negative predictive value $54.8 \%$. Overall diagnostic accuracy was found to be $69.0 \%$.

Table 3: Uterine artery resistive index analysis.

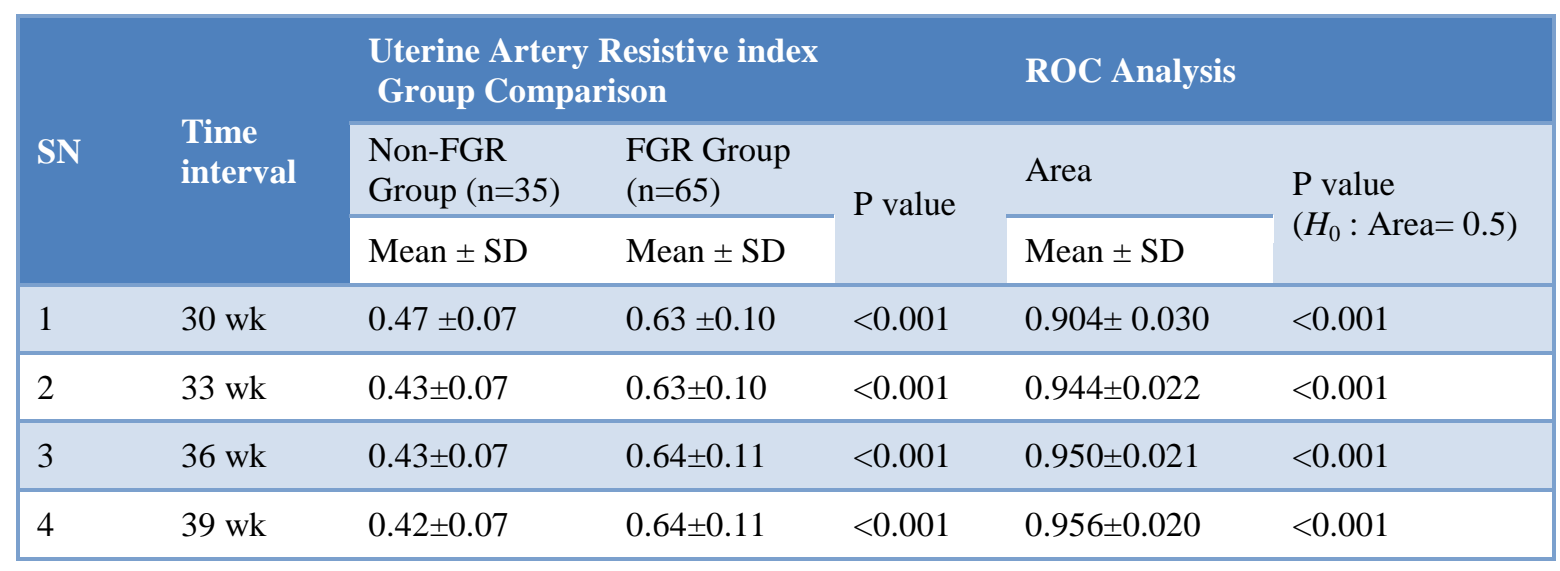

Uterine artery Resistive index(cut off value $>0.535$ at 30 weeks has sensitivity $84.6 \%$, specificity $82.9 \%$ with a positive predictive value $90.2 \%$ and negative predictive value $74.4 \%$. Overall diagnostic accuracy was found to be $84.0 \%$.

Table 4: Uterine artery pulsatility index analysis.

\begin{tabular}{|c|c|c|c|c|c|c|}
\hline \multirow{3}{*}{ SN } & \multirow{3}{*}{$\begin{array}{l}\text { Time } \\
\text { interval }\end{array}$} & \multicolumn{3}{|c|}{$\begin{array}{l}\text { Uterine Artery Pulsatility index Group } \\
\text { Comparison }\end{array}$} & \multicolumn{2}{|l|}{ ROC Analysis } \\
\hline & & $\begin{array}{l}\text { Non-FGR } \\
\text { Group }(n=35)\end{array}$ & $\begin{array}{l}\text { FGR Group } \\
(n=65)\end{array}$ & \multirow{2}{*}{$\mathrm{P}$ value } & Area & \multirow{2}{*}{$\begin{array}{l}\mathrm{P} \text { value }\left(H_{0}:\right. \\
\text { Area }=0.5)\end{array}$} \\
\hline & & Mean \pm SD & Mean \pm SD & & Mean \pm SD & \\
\hline 1 & $30 \mathrm{wk}$ & $0.81 \pm 0.20$ & $1.23 \pm 0.27$ & $<0.001$ & $0.878 \pm 0.033$ & $<0.001$ \\
\hline 2 & 33 wk & $0.70 \pm 0.19$ & $1.19 \pm 0.25$ & $<0.001$ & $0.924 \pm 0.025$ & $<0.001$ \\
\hline 3 & $36 \mathrm{wk}$ & $0.66 \pm 0.19$ & $1.26 \pm 0.31$ & $<0.001$ & $0.941 \pm 0.022$ & $<0.001$ \\
\hline 4 & 39 wk & $0.57 \pm 0.20$ & $1.26 \pm 0.31$ & $<0.001$ & $0.962 \pm 0.016$ & $<0.001$ \\
\hline
\end{tabular}

Uterine artery pulsatility index (cut off value $>1.03$ at 33 weeks) has a sensitivity $76.9 \%$, specificity $82.9 \%$ with a positive predictive value $89.3 \%$ and negative predictive value $65.9 \%$. Overall diagnostic accuracy was found to be $79.0 \%$. 
Table 5: Middle cerebral artery resistive index analysis.

\begin{tabular}{|c|c|c|c|c|c|c|}
\hline \multirow{3}{*}{ SN } & \multirow{3}{*}{$\begin{array}{l}\text { Time } \\
\text { interval }\end{array}$} & \multicolumn{3}{|c|}{$\begin{array}{l}\text { Middle cerebral artery resistive index - } \\
\text { Group Comparison }\end{array}$} & \multicolumn{2}{|l|}{ ROC Analysis } \\
\hline & & $\begin{array}{l}\text { Non-FGR } \\
\text { Group }(n=35)\end{array}$ & $\begin{array}{l}\text { FGR Group } \\
(n=65)\end{array}$ & \multirow{2}{*}{$P$ value } & Area & \multirow{2}{*}{$\begin{array}{l}\text { P value }\left(H_{0}\right. \\
: \text { Area }=0.5)\end{array}$} \\
\hline & & Mean $\pm \mathrm{SD}$ & Mean \pm SD & & Mean \pm SD & \\
\hline 1 & $30 \mathrm{wk}$ & $0.87 \pm 0.09$ & $0.97 \pm 0.22$ & 0.021 & $0.636 \pm 0.054$ & 0.025 \\
\hline 2 & $33 \mathrm{wk}$ & $0.91 \pm 0.15$ & $1.04 \pm 0.30$ & 0.019 & $0.618 \pm 0.056$ & 0.053 \\
\hline 3 & $36 \mathrm{wk}$ & $0.81 \pm 0.11$ & $0.95 \pm 0.26$ & 0.002 & $0.680 \pm 0.052$ & 0.003 \\
\hline 4 & $39 \mathrm{wk}$ & $0.83 \pm 0.10$ & $0.99 \pm 0.24$ & $<0.001$ & $0.716 \pm 0.050$ & 0.000 \\
\hline
\end{tabular}

Middle cerebral artery resistive index (cut off value $>0.86$ at 36 week) has sensitivity $60 \%$, specificity $71.4 \%$ with a positive predictive value $79.96 \%$ and negative predictive value $79 \%$. Overall diagnostic accuracy was found to be $64 \%$.

Table 6: Middle cerebral artery pulsatility index analysis.

\begin{tabular}{|c|c|c|c|c|c|c|}
\hline \multirow{3}{*}{ SN } & \multirow{3}{*}{$\begin{array}{l}\text { Time } \\
\text { interval }\end{array}$} & \multicolumn{3}{|c|}{$\begin{array}{l}\text { Middle cerebral artery pulsatility index - } \\
\text { Group Comparison }\end{array}$} & \multicolumn{2}{|l|}{ ROC Analysis } \\
\hline & & $\begin{array}{l}\text { Non-FGR } \\
\text { Group }(n=35)\end{array}$ & $\begin{array}{l}\text { FGR Group } \\
(\mathrm{n}=65)\end{array}$ & \multirow{2}{*}{$\mathrm{P}$ value } & Area & \multirow{2}{*}{$\begin{array}{l}\mathrm{P} \text { value }\left(H_{0}\right. \\
: \text { Area }= \\
0.5)\end{array}$} \\
\hline & & Mean \pm SD & Mean \pm SD & & Mean \pm SD & \\
\hline 1 & $30 \mathrm{wk}$ & $1.96 \pm 0.47$ & $2.06 \pm 0.50$ & 0.321 & $0.565 \pm 0.060$ & 0.286 \\
\hline 2 & 33 wk & $1.80 \pm 0.50$ & $2.02 \pm 0.51$ & 0.041 & $0.632 \pm 0.058$ & 0.030 \\
\hline 3 & 36 wk & $1.72 \pm 0.45$ & $2.11 \pm 0.52$ & $<0.001$ & $0.727 \pm 0.053$ & 0.000 \\
\hline 4 & 39 wk & $1.62 \pm 0.42$ & $2.06 \pm 0.55$ & $<0.001$ & $0.757 \pm 0.050$ & 0.000 \\
\hline
\end{tabular}

Middle cerebral artery pulsatility index (cut off value $>1.88$ at 36 week) has sensitivity $66.2 \%$, specificity $68.6 \%$ with a positive predictive value $79.6 \%$, negative predictive value $52.2 \%$. Overall Diagnostic accuracy was found to be $65.0 \%$.

Table 7: Middle cerebral artery PSV in two groups at different time intervals.

\begin{tabular}{|c|c|c|c|c|c|c|c|c|c|c|c|}
\hline \multirow{3}{*}{ SN } & \multirow{3}{*}{$\begin{array}{l}\text { Time } \\
\text { interval }\end{array}$} & \multicolumn{4}{|c|}{ Non-FGR Group (n=35) } & \multicolumn{4}{|c|}{ FGR Group $(n=65)$} & \multicolumn{2}{|c|}{$\begin{array}{l}\text { Statistical } \\
\text { significance }\end{array}$} \\
\hline & & \multirow{2}{*}{ Mean } & \multirow{2}{*}{ SD } & \multicolumn{2}{|l|}{$95 \% \mathrm{CI}$} & \multirow{2}{*}{ Mean } & \multirow{2}{*}{ SD } & \multicolumn{2}{|l|}{$95 \% \mathrm{CI}$} & \multirow{2}{*}{ "t" } & \multirow{2}{*}{ "p" } \\
\hline & & & & Lower & Upper & & & LOWER & Upper & & \\
\hline 1 & $30 \mathrm{wk}$ & 46.16 & 11.29 & 1.91 & 42.28 & 47.90 & 8.99 & 1.11 & 45.67 & 0.842 & 0.402 \\
\hline 2 & $33 \mathrm{wk}$ & 48.13 & 12.12 & 2.05 & 43.97 & 49.24 & 9.93 & 1.23 & 46.78 & 0.490 & 0.625 \\
\hline 3 & $36 \mathrm{wk}$ & 51.69 & 13.70 & 2.32 & 46.98 & 55.26 & 13.01 & 1.61 & 52.04 & 1.288 & 0.201 \\
\hline 4 & $39 \mathrm{wk}$ & 60.81 & 16.22 & 2.74 & 55.23 & 60.03 & 15.49 & 1.92 & 56.19 & 0.235 & 0.815 \\
\hline \multicolumn{2}{|c|}{$\begin{array}{l}\text { Correlation } \\
\text { With time }\end{array}$} & 0.360 & & & & 0.369 & & & & & \\
\hline
\end{tabular}


Table 8: Pregnancy outcome and mode of delivery.

\begin{tabular}{|llll|}
\hline SN & Parameter & $\begin{array}{l}\text { Non }- \\
\text { FGR } \\
(\mathbf{n = 3 5})\end{array}$ & FGR (n=65) \\
\hline 1 & $\begin{array}{l}\text { Vaginal } \\
\text { delivery }\end{array}$ & $21(60 \%)$ & $25(38.46 \%)$ \\
\hline 2 & $\begin{array}{l}\text { Caesarean } \\
\text { delivery }\end{array}$ & $14(40 \%)$ & $40(61.54 \%)$ \\
\hline
\end{tabular}

Table: 9 Perinatal outcome.

\begin{tabular}{|lllll|}
\hline SN & $\begin{array}{l}\text { Perinatal } \\
\text { outcome }\end{array}$ & $\begin{array}{l}\text { Non-FGR } \\
(\mathbf{n = 3 5})\end{array}$ & FGR (n=65) & "p" value \\
\hline 1 & $\begin{array}{l}\text { Admission } \\
\text { to NICU }\end{array}$ & 0 & $18(27.69 \%)$ & 0.001 \\
\hline 2 & $\begin{array}{l}\text { Neonatal } \\
\text { death }\end{array}$ & $1(2.86 \%)$ & $4(6.15 \%)$ & $\begin{array}{l}0.471 \\
(\mathrm{NS})\end{array}$ \\
\hline
\end{tabular}

Uterine artery: Mean resistive index in uterine artery amongst non FGR group was found to be significantly lower as compared to FGR group at all gestational ages.

At 30 weeks RI value $>0.535$ was found to be $84.6 \%$ sensitive, $82.9 \%$ specific with a positive predictive value of $90.2 \%$ and a negative predictive value of $74.4 \%$. Overall efficacy was assessed to be $84 \%$.The mean PI in Non FGR group was maximum at30 weeks $(0.81 \pm 0.20$; 95\% CI 0.75-0.88) and thereafter it showed a regular decrease till 39 weeks, when it was recorded as $(0.57 \pm 0.20 ; 95.5 \%$ CI $0.50-0.64)$

However in FGR group, it was found to be minimum at 33 weeks (1.19 \pm 0.25 ; CI 1.12-1.25) and maximum at 36 and 39 weeks $(1.26 \pm 0.31 ; 95 \%$ CI 1.18-1.34). A mild negative correlation $(r=-0.488)$ between gestational age and pulsatility index was seen in non FGR group, however in FGR group it was seen to be almost stable $(r=0.070)$. Considering the early detectability and accuracy, the 30 weeks cut off was evaluated. The 30 weeks PI $>1.03$ showed to be $76.9 \%$ sensitive, $82.9 \%$ specific with a positive predictive value of $89.3 \%$ and a negative predictive value of $65.9 \%$. Overall diagnostic efficacy of the test was found to be $79 \%$.

Middle cerebral artery: The mean RI in non FGR group was maximum at 33 weeks $(0.91 \pm 0.15)$ and thereafter it showed a decline to finally reach to $0.83 \pm 0.10$ at 39 weeks. In FGR group the mean RI was maximum at 33 weeks $(1.04 \pm 0.30)$ and minimum at 36 weeks $(0.95 \pm 0.26)$. Receiver operator curve analysis showed a maximum area under curve at 39 weeks (0.716) while minimum area under curve was seen at 30 weeks (0.646). At 36 weeks the cut off value of 0.86 was predicted to be $61.6 \%$ sensitive and $71.4 \%$ specific with a positive predictive value of $79.6 \%$ and a negative predictive value of $49.0 \%$. Overall diagnostic efficacy of the test was found to be $64 \%$. Statistically significant difference in PI of two groups was seen at all time intervals except at 30 weeks. A week negative correlation between time and PI was observed in non FGR group where as in FGR group the correlation was almost negligible. It was observed that difference between two groups were maximum at 39 weeks when the mean PI value in non FGR was $(1.60 \pm 0.42)$ and $(2.06 \pm 0.55$ in FGR group). Receiver operator curve analysis showed maximum area under curve at 39 weeks (0.757) while minimum area under curve was seen at 30 weeks $(0.565)$. At 36 weeks the cut off value of 1.88 was predicted to be $67.7 \%$ sensitive and $68.7 \%$ specific. The 36 weeks cut off value was evaluated further for diagnostic accuracy. The 36 weeks PI $>1.88$ showed to be $66.2 \%$ sensitive, $68.6 \%$ specific with a positive predictive value of $79.6 \%$ and a negative predictive value of $52.2 \%$. Overall diagnostic accuracy of the test was found to be $67 \%$. No statistically significant difference between two groups was observed as regards PSV at different time intervals. The mean PSV in both the groups was minimum at 30 weeks and maximum at 39 weeks. As no significant differences were observed between two groups at different time intervals, hence they were not further explored.

Table 10: Diagnostic efficacy of color Doppler at different gestational ages.

\begin{tabular}{|llllllll|}
\hline SN & Method & $\begin{array}{l}\text { Gestational } \\
\text { age (weeks) }\end{array}$ & Sensitivity & Specificity & PPV & NPV & $\begin{array}{l}\text { Diagnostic } \\
\text { Accuracy }\end{array}$ \\
\hline 1 & Uterine artery RI & 30 & 84.6 & 82.9 & 90.2 & 74.4 & 84 \\
\hline 2 & Uterine artery PI & 30 & 76.9 & 82.9 & 89.3 & 65.9 & 79.0 \\
\hline 3 & Umbilical artery RI & 30 & 80.0 & 74.3 & 85.2 & 66.7 & 78.0 \\
\hline 4 & $\begin{array}{l}\text { Umbilical artery } \\
\text { SD Ratio }\end{array}$ & 33 & 70.8 & 65.7 & 79.3 & 54.8 & 69.0 \\
\hline 5 & MCA RI & 36 & 60.0 & 71.4 & 79.6 & 49.0 & 64.0 \\
\hline 6 & MCA PI & 36 & 66.2 & 68.6 & 79.6 & 52.2 & 67.0 \\
\hline 7 & MCA PSV: & & $\begin{array}{l}\text { Values almost the same in all observed gestational ages, hence not } \\
\text { explored further }\end{array}$
\end{tabular}


Majority of subjects in both groups had vaginal delivery. There were $14(40 \%)$ caesarean delivery in non FGR group and $40(61.54 \%)$ in FGR group. The incidence of caesarean delivery was significantly higher in FGR group as compared to non FGR group $(\mathrm{P}<0.001)$. There were $18(27.7 \%)$ neonates in FGR group who were admitted to NICU as against none in non FGR group, this showing a statistically significant difference between two groups. In total 5 neonatal death took place, of these $1(2.86 \%)$ was in non FGR group while the remaining $4(6.15 \%)$ were in FGR group.

\section{DISCUSSION}

Fetal growth restriction is a condition in which fetus does not reach its growth potential. It is a pathological condition strongly related to the development and function of the utero-placental and feto-placental circulation. An adequate fetal circulation is necessary for normal fetal growth . To facilitate this remarkable changes occur in the maternal, placental and fetal vasculatures. Doppler waveform analysis has definite role in obstetrics especially in the diagnosis of placental insufficiency and in establishing prognosis. Doppler velocimetry has improved our understanding of the patho-physiological processes leading to IUGR and our possibilities of monitoring fetal health.

In umbilical artery, the 30 week RI $>0.68$ showed to be $80.0 \%$ sensitive, $74.3 \%$ specific with a positive predictive value of $85.2 \%$ and a negative predictive value of $66.7 \%$. Overall diagnostic efficacy of the test was found to be $78 \%$. North et $\mathrm{al}^{2}$ (1994) reported a sensitivity of $47 \%$ and a specificity of $91 \%$ for prediction of FGR. In present study, a relatively higher diagnostic efficacy was achieved, though the specificity was lower as compared to that of North yet the sensitivity was quite high. In the study of Kurmanavicius et $\mathrm{al}^{3}$ the $95 \%$ percentile value of RI for umbilical artery at 30 week was found to be 0.9 .

Statistically significant difference in umbilical artery SD ratio of two groups was seen at all time intervals. The 33 weeks SD ratio $>3.13$ showed to be $70.8 \%$ sensitive, $65.7 \%$ specific with a positive predictive value of $79.3 \%$ and a negative predictive value of $54.8 \%$. Overall diagnostic accuracy of the test was found to be $69 \%$. The umbilical artery SD ratio was found to be $66.6 \%$ sensitive and $45.4 \%$ specific for adverse perinatal outcome by lekhkar et al. ${ }^{4}$ The present study reports a better efficacy as compared to that reported by Lakhkar et al.

Mean RI in uterine artery amongst non FGR group was found to be significantly lower as compared to FGR group at all gestational ages. In non FGR group with the progression of the pregnancy, the RI was found to be decreasing. At 30 week RI value $>0.535$ was found to be $84.6 \%$ sensitive, $82.9 \%$ specific with a positive predictive value of $90.2 \%$ and a negative predictive value of $74.4 \%$.
Overall diagnostic efficacy was assessed to be $84 \%$. Kurmanavicius et al in their study have shown resistive index to be decreasing slightly with increasing gestational age between 30-38 weeks of gestation. In present study too, a slight decrease in RI was seen in from 30-39 weeks. Our results are in close proximity with the results of Lakhkar et al who reported a mean value of 0.49 in normal and 0.65 in abnormal pregnancy group at 28 weeks and 0.45 in normal and 0.64 in abnormal pregnancy at 34 weeks. In present study, at 30 weeks the mean value in non FGR group was 0.47 and in FGR group was 0.63 . The value decreased to 0.42 at 39 week in Non FGR group, but in FGR group it was found to be 0.64 showing a slight increment. Dugoff et $\mathrm{al}^{5}$ in their study showed that women with a high uterine artery mean $\mathrm{RI}\left(>75^{\text {th }}\right.$ percentile) even at first trimester were 5.5 times more likely to have IUGR as compared to lower uterine artery mean RI. Chung et al showed that uterine artery value >0.6 between 26-28 weeks gestation was an evidence of abnormal Doppler velocimetry and had an increase incidence of FGR. Statistically significant difference in uterine artery pulsatility index of two groups was seen at all time intervals. A mild negative correlation $(\mathrm{r}=0.408)$ between gestational age and pulsatility index was seen in non FGR group, however in FGR group it was seen to be almost stable $(\mathrm{r}=0.070)$. The 30 weeks PI $>1.03$ showed to be $76.9 \%$ sensitive, $82.9 \%$ specific with a positive predictive value of $89.3 \%$ and a negative predictive value of $65.9 \%$. Overall diagnostic efficacy of the test was found to be $79 \%$. Lakhkar et al showed a significant difference in mean PI of FGR and non-FGR groups. In their study too mean PI in normal pregnancy showed a continuous decrease from 28 week to 38 weeks while in FGR group the mean PI remained almost stable as in our study. Lubra et $\mathrm{al}^{6}$ (2009) showed that PI had a sensitivity of $73 \%$ in detection of IUGR. In present study, we found a sensitivity of above $76 \%$ for 30 week PI value.

For middle cerebral artery, the 36 weeks RI $>0.86$ showed to be $60.0 \%$ sensitive, $71.4 \%$ specific with a positive predictive value of $79.6 \%$ and a negative predictive value of $49.0 \%$. Overall diagnostic efficacy was found to be $64 \%$. The $95^{\text {th }}$ percentile MCA RI at 36 weeks as obtained by Tarzmani et $\mathrm{al}^{7}$ (2008 was obtained to be 0.88 which is too close to the calculated cut off value in present study. Kurmanavicius et al too reported a $95^{\text {th }}$ percentile value above 0.81 for MCA RI, thereby indicating that all these findings were suggestive of similar pattern. Statistically significant difference in PI of two groups was seen at all time intervals except at 30 weeks. A week negative correlation between time and PI was observed in non FGR group whereas in FGR group the correlation was almost negligible. It was observed that the differences between two groups were maximum at 39 weeks. The 36 week PI $>1.88$ showed to be $66.2 \%$ sensitive, $68.6 \%$ specific with a positive predictive value of $79.6 \%$ and a negative predictive value of $52.2 \%$. 
Overall diagnostic efficacy of the test was found to be $67 \%$. Tarazamni et al reported a $90^{\text {th }}$ percentile value of MCA PI at 36 weeks to be 2.20 which is well above the cut off level in the present study. The middle cerebral artery PSV did not show a significant difference between two groups, hence it was not explored further. Mari G et al Observed that low MCA PI and MCA PSV might be valuable in clinical assessment of FGR fetuses that have abnormal UA Doppler.

The outcome in terms of mode of delivery revealed a significantly higher incidence of caesarean delivery in FGR group as compared to non FGR group. The reason for this could be imminent fetal distress. Though the proportion of FGR babies admitted to NICU was significantly higher as compared to Non FGR group, yet no significant difference was observed between two groups in terms of neonatal death. This indicates that with accurate diagnosis and adequate availability of hospital facilities, the FGR babies could be managed perinatally for a better outcome.

\section{CONCLUSIONS}

On the basis of observation made during the course of study the following conclusion were drawn.

- Doppler measurement for uterine artery showed higher efficacy as compared to umbilical artery and middle cerebral artery findings. The uterine artery RI was found to be $84.6 \%$ sensitive and $82.9 \%$ specific even at 30 weeks.

- Uterine artery PI too showed a good diagnostic efficacy with an accuracy of $79 \%$, a sensitivity of $76.9 \%$, a specificity of $82.9 \%$.

- Both PI and RI for uterine artery showed a relatively higher specificity.

- Among different umbilical artery measurements, umbilical artery RI was observed to be most efficient even at early stage (30) weeks. It showed a sensitivity of $80 \%$ and specificity of $74.3 \%$ and overall diagnostic accuracy of $78 \%$.

- Umbilical artery SD ratio had a sensitivity of $67.7 \%$ and $70.8 \%$ and a specificity of $62.9 \%$ and $65.9 \%$ at 33 weeks.

- Middle cerebral artery RI and PI were found to show significant difference between non FGR and FGR groups and were observed to be $60 \%$ and $66.2 \%$ sensitive and $71.4 \%$ and $68.6 \%$ specific at 36 weeks.

\section{ACKNOWLEDGMENTS}

Authors are grateful to Dr. R K Bundela, Dr. D K Misra and $\mathrm{Mr}$ Zeshan for critical analysis and statistical analysis.

Funding: None
Conflict of interest: None declared

Ethical approval: The study was approved by the Institutional Ethics Committee

\section{REFERENCES}

1. Battaglia FC, Lubchenco LO. A practical classification of newborn infants by weight and gestational age. J Pediatr 1967;71:159.

2. North RA, Ferrier CL long D, Townend K, Kincaidsmith F. Uterine artery Doppler flow velocity waveforms in the second trimester for the prediction of pre-eclampsia and fetal growth retardation. Obstet Gynecol 1994;83:378-86.

3. Lakhkar BN, Ahamed S. Doppler velocimetry of uterine and umbilical arteries during pregnancy. Indian J Radiol Imaging 1999; 9(3): 119-215.

4. Byun YJ, Kim HS, Yang JI et al Umbilical artery Doppler study as a predictive marker of perinatal outcome in preterm small for gestational age infants. Yonsi Med J 2009;50(1): 39- 44.

5. Kurmanavicius J, Florio I, Wisser J. Reference resistive indices of the umbilical, fetal middle cerebral and uterine arteries at 24-42 weeks gestation. Ultrasound Obstet Gynecol.1997; 10:112120.

6. Dugoff L, Lynch AM, Cioffi-Ragan D et al First trimester uterine artery Doppler abnormalities predict subsequent intrauterine growth restriction. Am. J. Obs. Gyn. 2005; 193(3):1208-1212.

7. Chung JE, Cho JS, Han SS parl YW, Kin JW. Uterine artery Doppler velocimetry in the prediction of adverse obstetrics outcomes in unexplained MSAFP elevations.Yonsi medical Journal. 2000; 41(1): 17 .

8. Obstetrics and Gynecology International. Maternal history and Uterine artery Doppler in the assessment of Risk for development of early and late onset preeclampsia and intrauterine growth restriction, 2009. Available at http://dx.doi.org/10.1155/ 2009/275613. Accessed 26 September 2013.

9. Tarzamni MK, Nezami N, Sobhani N et al Nomograms of Iranian fetal middle cerebral artery doppler waveforms and uniformity of their pattern with other populations' nomograms. BMC Pregnancy and childbirth 2008; 8:50.

10. Tarzamni MK, Nezami N, Gatreh-Samani F, Vahedinia S and Tarazmni M. Doppler Waveform Indices of fetal middle cerebral artery in normal 20 40 weeks pregnancies. Arch Iranian Med 2009; 12(1):29-34.

DOI: $10.5455 / 2320-1770 . i j r \operatorname{cog} 20131215$

Cite this article as: Singh $\mathrm{S}$, Verma U, Shrivastava

K, Khanduri S, Goel N, Zahra F, Shirivastava KL.

Role of color doppler in the diagnosis of intra uterine growth restriction (IUGR). Int J Reprod Contracept Obstet Gynecol 2013;2:566-72. 